\title{
Conjunctival Nevus
}

National Cancer Institute

\section{Source}

National Cancer Institute. Conjunctival Nevus. NCI Thesaurus. Code C4551.

A benign melanocytic neoplasm that arises from the conjunctiva. 